\title{
DESAIN KALORIMETER BOMB BIOMASSA DENGAN METODE OKSIGEN DINAMIK
}

\author{
OTONG NURHILAL*, SETIANTO, ANDA SUHANDA \\ Departemen Fisika Fakultas MIPA Universitas Padjadjaran, \\ Jl. Raya Bandung-Sumedang Km 21, Jatinangor 45363 \\ * email : otong.nurhilal@phys.unpad.ac.id
}

\begin{abstract}
Abstrak. Kandungan energi biomassa dapat diukur dengan kalorimeter bomb. Efektifitas kerja kalorimeter bomb ditentukan oleh proses terjadinya pembakaran sampel secara sempurna. Untuk menghasilkan pembakaran sempurna dibutuhkan tekanan yang cukup di dalam bomb kalorimeter tersebut. Cara konvensional adalah dengan memberikan oksigen secara statis hingga tercapai kondisi tekanan sekitar 30 atm. Cara non konvensional adalah dengan memberikan oksigen kedalam bomb secara kontinu (dinamis) hingga mencapai debit tertentu yang optimal. Pada penelitian ini telah dirancang kalorimeter bomb dengan sistem input oksigen secara kontinu. Untuk pencatatan perubahan temperatur air pada kalorimeter bomb digunakan sensor temperatur berbasis mikrokontroler arduino uno. Variasi debit oksigen yang diberikan adalah 3 liter/menit, 5 liter/menit dan 7 liter/menit. Sampel biomassa yang digunakan untuk pengujian adalah biobriket kulit kopi, biobriket tempurung kelapa dan biobriket kayu kaliandra. Hasil pengujian ketiga jenis biobriket tersebut diperoleh nilai kalor untuk kulit kopi, tempurung kelapa dan kayu kaliandra masing-masing adalah 3555,1 kal/gram, 3717,4 kal/gram dan 4085,8 kal/gram pada debit oksigen 7 liter/menit. Nilai kalor hasil pengujian ini mendekati nilai kalor ketiga jenis biobriket yang diuji dengan kalorimeter bomb standar.
\end{abstract}

Kata kunci : kalorimeter bomb, oksigen, biomassa, biobriket, nilai kalor

\begin{abstract}
The energy content of biomass can be measured by a bomb calorimeter. The effectiveness of bomb calorimeter is determined by the process of burning the sample completely. To produce a complete combustion takes considerable pressure in the bomb calorimeter. The convensional trick is to provide static oxygen until its pressure reachs about $30 \mathrm{~atm}$. The other trick is to provide oxygen into the bomb continuously (dynamically) until it reaches a certain optimum discharge. This study has been designed with a bomb calorimeter continuous oxygen input system. For recording changes in water temperature at the bomb calorimeter, microcontroller-based temperature sensor of arduino uno is used. Variations of oxygen debit is 3, 5 and 7 liters/minute. Biomass samples used for testing are biobriquette coffee skin, coconut shell and kaliandra. The result of test of the three types biobriquette are obtained the calorific values for coffee skin, coconut shell and kaliandra is $3555.1,3717.4$ and $4085.8 \mathrm{cal} /$ gram repectively on discharge oxygen 7 liters/minute. The calorific value of the results of test is approaching the calorific value of the three types biobriquette tested with standard bomb calorimeter.
\end{abstract}

Keywords : bomb calorimeter, oxygen, biomass, biobriquette, calorific value

\section{Pendahuluan}

Kalorimetri merupakan medan penting dalam kimia analitik yang menjanjikan pengukuran panas secara akurat dari suatu reaksi [1]. Reaksi yang menghasilkan 
panas diantaranya adalah reaksi pembakaran biomassa dengan melibatkan oksigen. Melalui reaksi pembakaran tersebut kandungan energi biomassa bisa diketahui.

Pemanfaatan biomassa sebagai sumber energi alternatif akan efektif apabila kandungan energinya diketahui. Kandungan energi biomassa dapat ditentukan nilainya dengan alat kalorimeter bomb. Prinsip kerja kalorimeter bomb adalah membakar sampel biomassa dan mengukur efek pembakarannya. Efek pembakaran sampel berupa panas yang menyebabkan kenaikan temperatur pada bejana (vessel) dan air disekitarnya.

Proses pembakaran sampel biomassa dipengaruhi oleh jumlah oksigen pada bejana. Untuk mendapatkan pembakaran sempurna sampel biomassa harus berada pada lingkungan oksigen yang terkompresi statis di dalam bejana pada tekanan tertentu dan bersifat adiabatik. Standar tekanan oksigen statik pada bejana adalah 25-30 atm [2]. Metode pembakaran sampel biomassa seperti ini disebut dengan metode oksigen statik. Dalam proses pembakaran metode oksigen statik memerlukan bejana dengan disain khusus yang mampu menahan kekuatan tekanan statik yang telah ditetapkan.

Metode lain yang bisa digunakan dalam proses pembakaran sampel biomassa adalah metode oksigen dinamik. Pada metode ini oksigen diatur dan dialirkan ke bejana secara kontinu pada debit tertentu selama proses pembakaran dengan menjaga tekanan tetap konstan sehingga perubahan energi dalamnya sama dengan perubahan entalpinya. Permasalahannya adalah berapa nilai debit oksigen optimal agar proses pembakaran sampel biomassa mendekati kondisi pembakaran sempurna sebagaimana pada metode oksigen statik.

Pada penelitian ini telah dirancang kalorimeter bomb dengan metode oksigen dinamik. Selama proses pembakaran berlangsung diberikan input oksigen secara kontinu pada debit tertentu. Untuk pencatatan perubahan temperatur selama proses pembakaran digunakan sensor temperatur berbasis mikrokontroler arduino uno. Tujuan penelitian ini adalah menentukan nilai debit oksigen optimal yang mendekati proses pembakaran sempurna.

\section{Metode Penelitian}

Berdasarkan hukum pertama termodinamika perubahan energi dalam $(\Delta U)$ bergantung pada transfer kalor antara sistem dan lingkungan $\left(q_{\text {sist }}<0\right.$ dan $\left.q_{\text {lingk }}>0\right)$ dan kerja yang terjadi pada sistem $(w)[3]$.

$$
\Delta U=q_{\text {sist }}+w
$$

Jika diasumsikan bahwa hanya ada tekanan luar $\left(P_{\text {eskt }}\right)$ dan volume konstan $(\Delta V=0)$ maka kerja yang terjadi juga nol, maka;

$$
\Delta U=q_{\text {sist }}
$$

Pada kalorimeter bomb jika proses berlangsung secara adiabatik, perubahan temperatur yang terjadi bisa diukur. Jika kapasitas panas kalorimeter $\left(C_{k a l}\right)$ sebagai lingkungannya diketahui maka jumlah panas yang dilepas oleh bomb adalah:

$$
-q_{\text {sist }}=q_{\text {lingk }}=C_{\text {kal }} \Delta T_{\text {lingk }}
$$


Karakteristik perubahan temperatur sebelum, selama dan setelah proses pembakaran diilustrasikan dengan Gambar 1. Pendekatan sederhana untuk mendapatkan $\Delta T$ adalah:

$$
\Delta T=T_{c}-T_{a}
$$

Namun dikarenakan temperatur tidak stabil pada periode awal $(i<t<a)$ dan akhir $(f<t<c)$, sehingga memerlukan faktor koreksi garis bawah (baseline correction). Jika garis bawah dianggap linier maka laju perubahan dapat diperoleh dengan pendekatan berikut [3]:

$$
r_{1} \approx \frac{T_{a}-T_{i}}{5} \text { dan } \quad r_{2} \approx \frac{T_{f}-T_{c}}{5}
$$

sehingga:

$$
\Delta T=T_{c}-T_{a}-r_{1}\left(t_{b}-t_{a}\right)-r_{2}\left(t_{c}-t_{b}\right)
$$

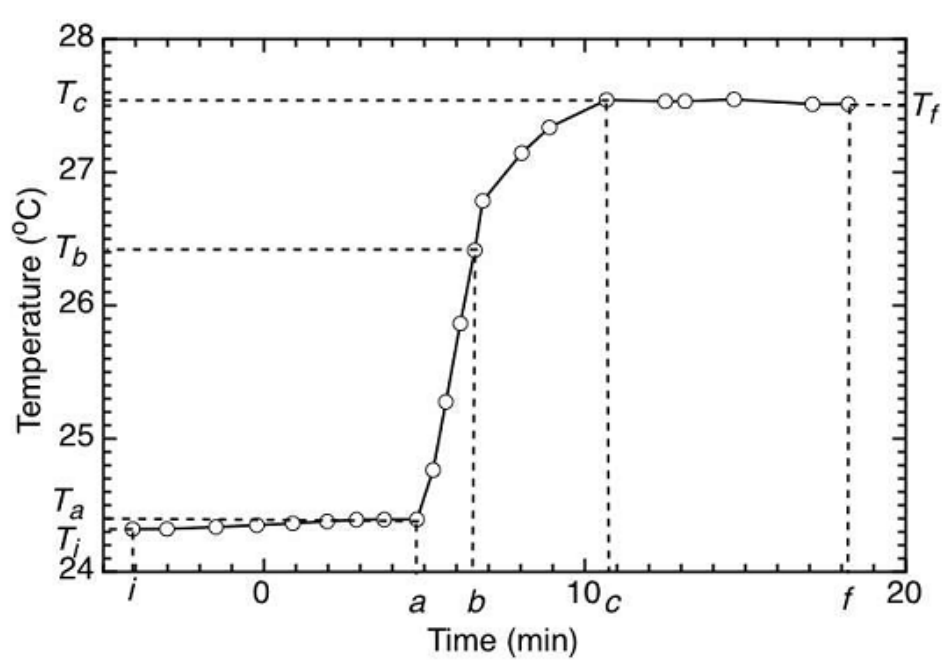

Gambar 1. Karakteristik perubahan temperatur standar [4].

Nilai kalor biomassa dapat dihitung dengan persamaan[4];

$$
Q_{g}=\frac{\Delta T \cdot W-e_{1}-e_{2}}{m}
$$

dengan $W$ adalah kesetaraan energi $\left(2426 \mathrm{kal} /{ }^{\circ} \mathrm{C}\right)$ asam benzoat, $m$ adalah massa sampel biomassa (gram), $e_{1}$ adalah koreksi panas titrasi asam nitrat, $e_{2}$ adalah koreksi panas filamen pembakar dan $\Delta T$ adalah kenaikan temperatur koreksi. Nilai kesetaraan energi dihitung dengan rumus [4],

$$
W=\frac{H \cdot m+e_{1}+e_{2}}{\Delta T}
$$

dengan $H$ adalah panas pembakaran standar asam benzoat (6318 kalori/gram), $m$ adalah massa asam benzoat (1,1651 gram), $e_{1}$ adalah koreksi panas pembentukan asam nitrat $(1 \mathrm{kal} / \mathrm{ml}), e_{2}$ adalah koreksi panas filamen pembakar $(2,3 \mathrm{kal} / \mathrm{cm})$ dan $\Delta T$ adalah kenaikan temperatur selama pembakaran asam benzoat $\left(3,047^{\circ} \mathrm{C}\right)$. 
Perancangan dimulai dengan perancangan satu set kalorimeter bomb yang meliputi perancangan kalorimeter bomb (a), elektroda dan cawan sampel (b) dan dua lubang untuk input dan outpun oksigen (c).

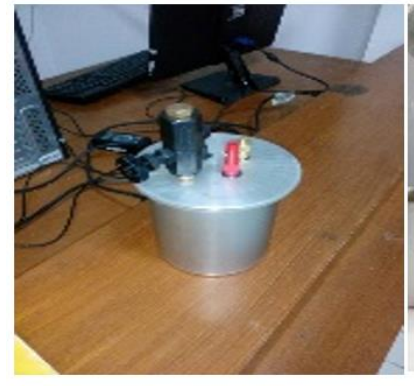

(a)

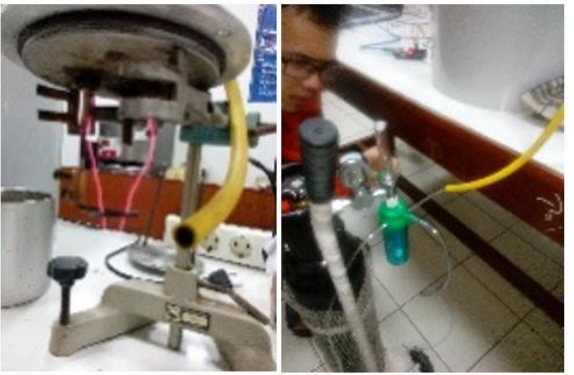

(b) (c)

Gambar 2. Komponen utama kalorimeter bomb

Berikutnya adalah perancangan tabung penampung air (bucket) dan instrumentasi sensor temperatur serta sensor gas yang bekerja dengan bantuan mikrokontroler arduino uno. Agar instrumentasi tersebut memiliki ketepatan dalam proses pengukurannya maka terlebih dahulu dilakukan kalibrasi baik untuk sensor temperatur maupun sensor gas. Tahap selanjutnya adalah pengujian alat kalorimeter bomb untuk mengukur nilai kalor biomassa berupa biobriket yang terbuat dari bahan dasar kulit kopi, kayu kaliandra dan tempurung kelapa. Hasil pengukuran nilai kalor biomassa dibandingkan dengan hasil pengukuran dengan kalorimeter bomb standar.

\section{Hasil dan Pembahasan}

Ada dua sensor suhu yang dikalibrasi yaitu jenis DS18B20 dan MAX6675. Kalibrasi dilakukan dengan cara membandingkan data pengukuran dengan data alat ukur konvensional yaitu multimeter. Perbandingan data pengukuran ditampilkan pada Gambar 3.

Berdasarkan Gambar 3 terlihat bahwa untuk rentang suhu 0 sampai $50^{\circ} \mathrm{C}$ nilai pengukuran sensor DS18B20 lebih mendekati nilai pengukuran multimeter dibandingkan dengan nilai pengukuran sensor MAX6675. Oleh karena itu jenis sensor temperatur yang digunakan adalah sensor DS18B20.

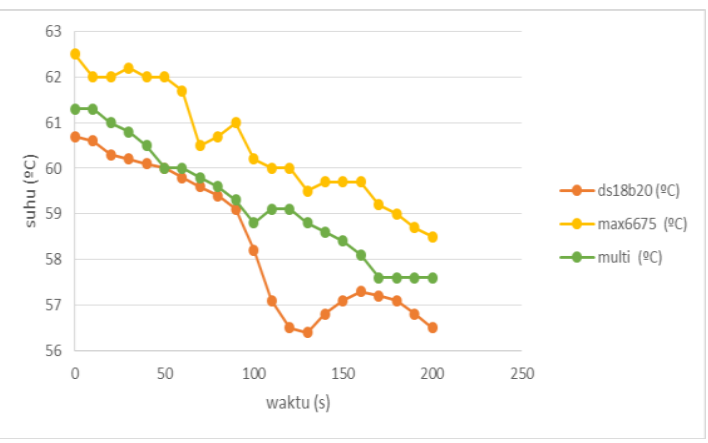

Gambar 3. Grafik perbandingan data sensor DS18B20, MAX6675 dan multimeter 
Sebelum proses pembakaran, sampel ditimbang dengan timbangan digital dengan berat mendekati 1 gram. Dua liter air dimasukkan kedalam bejana air dan bomb dimasukkan kedalam bejana air tersebut. Oksigen dimasukkan kedalam bomb dimana sampel dan filamen pembakar sudah dipersiapkan di dalamnya. Sensor temperatur dijalankan selama lima menit sebelum pembakaran hingga 5 menit setelah pembakaran. Total waktu pencatatan temperatur sekitar 18 menit.

Berdasarkan data perubahan temperatur dihitung perubahan temperatur koreksi dengan persamaan (5) dan (6). Selanjutnya dihitung nilai kalor dengan persamaan (7). Hasil perhitungan nilai kalor sampel biobriket kulit kopi, kayu kaliandra dan tempurung kelapa ditampilkan pada tabel 1 berikut.

Tabel 1. Hasil perhitungan nilai kalor biobriket

\begin{tabular}{llcccc}
\hline \multirow{2}{*}{ No. } & \multirow{2}{*}{ Biobriket } & \multirow{2}{*}{ Perekat } & \multicolumn{3}{c}{ Nilai Kalor (kal/gram) } \\
\cline { 4 - 6 } & & $0 \%$ & $3 \mathrm{~L} / \mathrm{min}$ & $5 \mathrm{~L} / \mathrm{min}$ & $7 \mathrm{~L} / \mathrm{min}$ \\
\hline 1 & Kulit Kopi & $0 \% 81,3$ & - & 3555,1 \\
2 & Tempurung Kelapa & $0 \%$ & - & - & 3717,4 \\
3 & Kaliandra & $0 \%$ & - & - & 4085,8 \\
4 & Kaliandra & $20 \%$ & - & 2479,2 & 3666,8 \\
5 & Kaliandra & $25 \%$ & - & 1734,6 & 2580,3 \\
\hline
\end{tabular}

Berdasarkan hasil perhitungan nilai kalori seluruh sampel biobriket terlihat bahwa pemberian oksigen akan berpengaruh terhadap nilai kalor. Semakin banyak oksigen yang diberikan semakin naik nilai kalornya. Hal ini menujukkan bahwa oksigen membantu proses pembakaran yang sempurna, artinya seluruh sampel terbakar sehingga akan memberikan kalor yang maksimal baik kepada kalorimeter bomb maupun pada air. Idealnya oksigen yang dimasukkan pada kalorimeter bomb dibuat dalam keadaan statis pada tekanan hingga mencapai $35 \mathrm{~atm}$. Namun pada penelitian ini disebabkan harga pembuatan kalorimeter bomb yang standar internasional harganya sangat mahal maka kalorimeter bomb yang dibuat hanya aman pada tekanan 2 atm. Oleh karena itu pemberian oksigen kedalam kalorimeter bomb bersifat kontinu pada nilai debit tertentu.

Berdasarkan hasil perhitungan nilai kalor biobriket dengan variasi oksigen $3 \mathrm{~L} /$ menit, $5 \mathrm{~L} /$ menit dan $7 \mathrm{~L} /$ menit maka nilai kalor lebih tinggi diperoleh pada pemberian oksigen $7 \mathrm{~L} /$ menit.

Nilai kalor biobriket kulit kopi pada pemberian oksigen $7 \mathrm{~L} /$ menit telah mendekati nilai kalor hasil perhitungan dengan kalorimeter bomb standar [5]. Adapun untuk pemberian oksigen $3 \mathrm{~L} /$ menit nilai kalornya lebih kecil dari nilai standar. Untuk pemberian oksigen $5 \mathrm{~L} / \mathrm{m}$ tidak diperoleh data yang bagus hal ini diduga karena cawan yang digunakan temperaturnya masih tinggi setelah digunakan untuk proses pembakaran sebelumnya.

Untuk nilai kalor biobriket tempurung kelapa masih dibawah standar (5014 $\mathrm{kal} / \mathrm{gram}$ ). Jenis biobriket tempurung kelapa yang diuji adalah biobriket hasil pabrik yang telah dikarbonisasi sebelumnya dalam bentuk padat. Kepadatan inilah yang diduga menyebabkan lambatnya proses pembakaran. 
Untuk biobriket kayu kaliandra dalam bentuk pelet tanpa campuran perekat diperoleh nilai kalor 4085,8 kal/g. Hasil ini lebih besar dari nilai pengukuran standar yaitu $4021 \mathrm{kal} / \mathrm{gram}$ [6]. Sedangkan untuk pelet biobriket kayu kaliandra dengan variasi campuran kanji menunjukkan nilai kalor dibawah standar. Penambahan kadar perekat kemungkinan mengurangi nilai kalornya.

Dari hasil pengukuran dan perhitungan nilai kalor semua sampel biobriket selain dipengaruhi oleh optimalnya input oksigen di dalam bomb terdapat pula faktor lain yang mempengaruhi hasil perhitungan nilai kalor yaitu ketepatan menghitung temperatur koreksi. Nilai temperatur koreksi $(\Delta \mathrm{T})$ sangat bergantung pada ketepatan pencatatan temperatur dan waktu selama pengukuran berlangsung. Pada penelitian ini proses pencatatan temperatur selama proses pembakaran menggunakan sensor suhu yang dijalankan dengan mikrokontroler arduino uno. Oleh karena itu akurasi alat dan kalibrasinya sangat penting.

\section{Kesimpulan}

Berdasarkan hasil dan pembahasan diperoleh kesimpulan bahwa kalorimeter bomb telah dirancang dan berhasil digunakan untuk menghitung nilai kalor sampel biobriket. Dalam proses pembakaran sampel digunakan debit oksigen secara dinamis dengan tiga variasi yaitu 3L/menit, 5L.menit dan 7L/menit. Dari beberapa sampel biobriket yang diuji debit oksigen $7 \mathrm{~L} /$ menit memberikan nilai kalor yang lebih tinggi.

\section{Ucapan terima kasih}

Terimakasih kepada Fakultas Matematika dan Ilmu Pengetahuan Alam dan Lembaga Penelitian dan Pengabdian pada Masyarakat Universitas Padjadjaran yang telah memberikan dana untuk penelitian ini melalui skema hibah pengembangan kapasitas riset dosen (HPKRD) tahun 2016.

\section{Nomenklatur:}

$T_{c}$ : temperatur tertinggi sampai konstan setelah pembakaran

$T_{a}$ : temperatur pada saat memulai pembakaran

$T_{i}$ : temperatur awal sebelum pembakaran

$T_{f}$ : temperatur akhir setelah pembakaran

$t_{a}:$ waktu pembakaran

$t_{b}:$ waktu temperatur mencapai $60 \%$ setelah kenaikan total

$t_{c}$ : waktu pada saat temperatur tertinggi setelah pembakaran

$r_{1}$ : faktor koreksi temperatur 5 menit sebelum pembakaran

$r_{2}$ : faktor koreksi temperatur 5 menit setelah pembakaran, negatif jika temperatur turun

\section{Daftar Pustaka}

1. J. Melville, Bomb Calorimetry and Heat of Combustion. UC Berkeley College of Chemistry (2014).

2. PARR INSTRUMENT COMPANY. Introduction to Bomb Calorimetry (2007).

3. R. J. Silbey, R. A. Alberty, and M. G. Bawendi, Physical Chemistry (4th ed.) Wiley, New York (2004). 
4. PARR INSTRUMENT COMPANY. Oxygen Bomb Calorimeter; Operating Instruction Manual, Parr No. 204. 2008.

5. L. Numan dkk, Pengaruh Penambahan Konsentrasi Kalsium Oksida pada Biobriket Berbahan Baku Kulit Kopi. p. 45, (2016).

6. P. K. Lisa dkk, Pengaruh Kadar Zat Perekat Terhadap Karakteristik Biopelet Kayu Kaliandra. p. 55, (2016). 